\title{
Adult Intussusception Caused by Descending Colon Cancer during Chemotherapy of Stomach Cancer Recurrence
}

\author{
Minoru Fukuchi $^{\mathrm{a}}$ Ritsuko Tsukagoshi ${ }^{\mathrm{a}}$ Shinji Sakurai ${ }^{\mathrm{b}}$

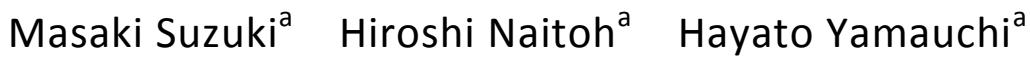 \\ Yuichi Tabe $^{a}$ Takaharu Fukasawa $^{a}$ Shinsuke Kiriyama ${ }^{a}$ \\ Hiroyuki Kuwanoc \\ Departments of ${ }^{a}$ Surgery and ${ }^{b}$ Diagnostic Pathology, Social Insurance Gunma \\ Chuo General Hospital, and ${ }^{~}$ Department of General Surgical Science, Gunma \\ University Graduate School of Medicine, Maebashi, Japan
}

\section{Key Words}

Intussusception · Descending colon cancer - Stomach cancer recurrence ·

Chemotherapy

\begin{abstract}
Intussusception in adults is uncommon, and it is rare in the descending colon because of its fixation to the retroperitoneum. We herein describe a case of intussusception caused by descending colon cancer. A 74-year-old man was admitted to our hospital for treatment of vomiting and abdominal pain. He had undergone chemotherapy for lymph node recurrence of stomach cancer for about 4 years. Computed tomography revealed a 'target mass' with a tumor in the descending colon. We diagnosed his illness as intussusception of a descending colon tumor and performed emergency laparotomy. Conservative resection was performed following anastomosis after reduction of the intussusception. The tumor was pathologically diagnosed as poorly differentiated adenocarcinoma with neuroendocrine features. To the best of our knowledge, this is the first report of an intussusception caused by descending colon cancer incidentally diagnosed during chemotherapy for stomach cancer recurrence.
\end{abstract}




\section{Introduction}

Intussusception is most commonly encountered in infants and children, although approximately $5 \%$ of cases occur in adults. In fact, it accounts for an estimated $1 \%$ of all cases of bowel obstruction in adults. Adult intussusception of the colon is rare and often originates from neoplasia [1]. This condition generally does not present with any specific symptoms. The diagnosis can be in emergency situations, with the aid of integrated examinations. The association of readily available diagnostic means, such as radiological and ultrasonographic studies, may yield reliable findings [2, 3]. These help in formulating a diagnosis of the nature and site of occlusion. However, this condition is often subsequently confirmed intraoperatively. Preoperative diagnosis of this condition can be difficult in emergency cases.

We herein describe a case of adult intussusception of the descending colon caused by a malignant tumor. Intussusception of the descending colon generally does not readily occur because the descending colon is anatomically fixed to the retroperitoneum [4]. Moreover, this patient had undergone chemotherapy for lymph node recurrence of stomach cancer for about 4 years, which could not prevent colon cancer. The progression of this patient's condition seemed to indirectly suggest a difference in biological malignancy between stomach cancer and colon cancer.

\section{Case Report}

A 74-year-old Japanese man was admitted to our hospital for treatment of vomiting and abdominal pain on June 15,2011 . Physical examination revealed a temperature of $36.9^{\circ} \mathrm{C}$, blood pressure of $175 / 105 \mathrm{~mm} \mathrm{Hg}$ and a pulse rate of 65 beats/min. His abdominal pain continued intermittently for approximately $12 \mathrm{~h}$ in the night. Clinical examination revealed a distended abdomen with provocative pain in the left upper quadrant and a palpable, fist-sized mass. Blood tests showed a slightly elevated C-reactive protein level of $1.15 \mathrm{mg} / \mathrm{dl}$, although other tests, including tumor markers, were within normal limits.

The patient had a past history of distal gastrectomy for stomach cancer in December 2003 and was visiting our hospital for chemotherapy for lymph node recurrence around the aorta approved since March 2007. This patient underwent 12 courses of irinotecan $\left(100 \mathrm{mg} / \mathrm{m}^{2}\right.$ weekly for 3 weeks followed by 2 weeks of rest) followed by 14 courses of $S-1\left(80 \mathrm{mg} / \mathrm{m}^{2}\right.$ weekly for 4 weeks followed by 2 weeks of rest) and 5 courses of paclitaxel $\left(100 \mathrm{mg} / \mathrm{m}^{2}\right.$ weekly for 3 weeks followed by 1 week of rest). Computed tomography (CT) indicated that the lymph node recurrence had disappeared on June 1, 2011, resulting in a complete response.

At his visit to our hospital, CT revealed a 'target mass' in the descending colon, suggesting the existence of a tumor in the head of the intussusception (fig. 1), whereas colonoscopic examination had revealed normal results in June 2008. We diagnosed his illness as intussusception of a colon tumor and performed emergency laparotomy. At surgery, the descending colon was intussuscepted into itself by the tumor. The intussusceptum was easily isolated because the fixation between the descending colon and the retroperitoneum was relatively weak. Reduction of the intussusception was performed before the resection following anastomosis because of the shortness and tension in the neighboring colon. The left colon, including the ischemic area and tumor, and regional lymph nodes were removed. An end-to-end anastomosis was primarily fashioned between the transverse colon and sigmoid colon. The postoperative course was uneventful, and the patient was discharged 14 days after surgery.

Macroscopically, the surgical specimen contained a $5.3 \times 3.5 \mathrm{~cm}$ protuberant tumor at the proximal edge of the 16-cm-long ischemic area in the descending colon (fig. 2). Microscopic examination revealed poorly differentiated adenocarcinoma with invasion into the subserosa and ischemic wall on the anal side of the tumor by hematoxylin-eosin staining (fig. $3 \mathrm{a}$ ). The regional 


\begin{tabular}{|c|c|c|c|}
\hline $\begin{array}{l}\text { Case Reports in } \\
\text { Gastroenterology }\end{array}$ & $\begin{array}{l}\text { Case Rep Gastroenterol 2012;6:88-93 } \\
\text { DOI: 10.1159/000336601 }\end{array}$ & $\begin{array}{l}\text { Published online: } \\
\text { January 31, } 2012\end{array}$ & $\begin{array}{l}\text { (c) } 2012 \text { S. Karger AG, Basel } \\
\text { ISSN } 1662-0631 \\
\text { www.karger.com/crg }\end{array}$ \\
\hline
\end{tabular}

lymph nodes did not have metastasis. The tumor was partially positive for chromogranin A, KIT, and CD56 by immunohistological staining, resulting in an adenocarcinoma with neuroendocrine features (fig. 3b-d).

\section{Discussion}

Most colon intussusceptions in adults are caused by malignant tumors, although other causes and idiopathic forms of intussusception have been reported [1-3]. These intussusceptions are frequently located in the flexible portions of the colon, for example the sigmoid colon or cecum [5, 6]. Intussusception of the descending colon is rarer because the descending colon is anatomically fixed to the retroperitoneum [4]. Incomplete fixation between the retroperitoneum and descending colon might result in the presently described condition.

Few general surgeons encounter more than one or two patients with colon intussusception during their careers, and most cases are undiagnosed before surgery. Previous papers reported that CT is the most accurate imaging modality for diagnosing intussusception $[1,2]$. The characteristic CT findings of intussusception include an early target mass with enveloped, eccentrically located areas of low density [7].

Reduction of intussusceptions with suspected malignancy is not generally advisable because it may cause bowel perforation and tumor cell dissemination [8]. However, reduction may be advisable to accurately determine the range of resection for minimally invasive surgery [6]. In our case, conservative resection was performed following anastomosis after reduction of the intussusception. If the intussusception had been operatively reduced, it would have been difficult to anastomose primarily because of the shortness and tension in the neighboring colon.

It was thought that colon cancer in this case occurred during the past 3 years, because colonoscopic examination had revealed a normal study in 2008. On the other hand, our patient had received several kinds of chemotherapy for lymph node recurrence of stomach cancer for about 4 years and had obtained a complete response. Thus chemotherapy seems to be generally effective for both gastric cancer and colon cancer, but could not prevent colon adenocarcinoma in our case. One reason could be the mixture of neuroendocrine features, because neuroendocrine carcinomas often show resistance to chemotherapy [9].

Colon intussusception in adults is generally rare. To the best of our knowledge, this is the first report of an intussusception caused by descending colon cancer incidentally diagnosed during chemotherapy for stomach cancer recurrence. The progression of this patient's condition also suggested a difference in the biological malignancy between stomach cancer and colon cancer.

\section{Disclosure Statement}

The authors have no conflicts of interest. 


\begin{tabular}{r|l|l|l}
$\begin{array}{r}\text { Case Reports in } \\
\text { Gastroenterology }\end{array}$ & $\begin{array}{l}\text { Case Rep Gastroenterol 2012;6:88-93 } \\
\text { DOI: 10.1159/000336601 }\end{array}$ & $\begin{array}{l}\text { Published online: } \\
\text { January 31, 2012 }\end{array}$ & $\begin{array}{l}\text { @ 2012 S. Karger AG, Basel } \\
\text { ISSN 1662-0631 } \\
\text { www.karger.com/crg }\end{array}$ \\
\hline
\end{tabular}
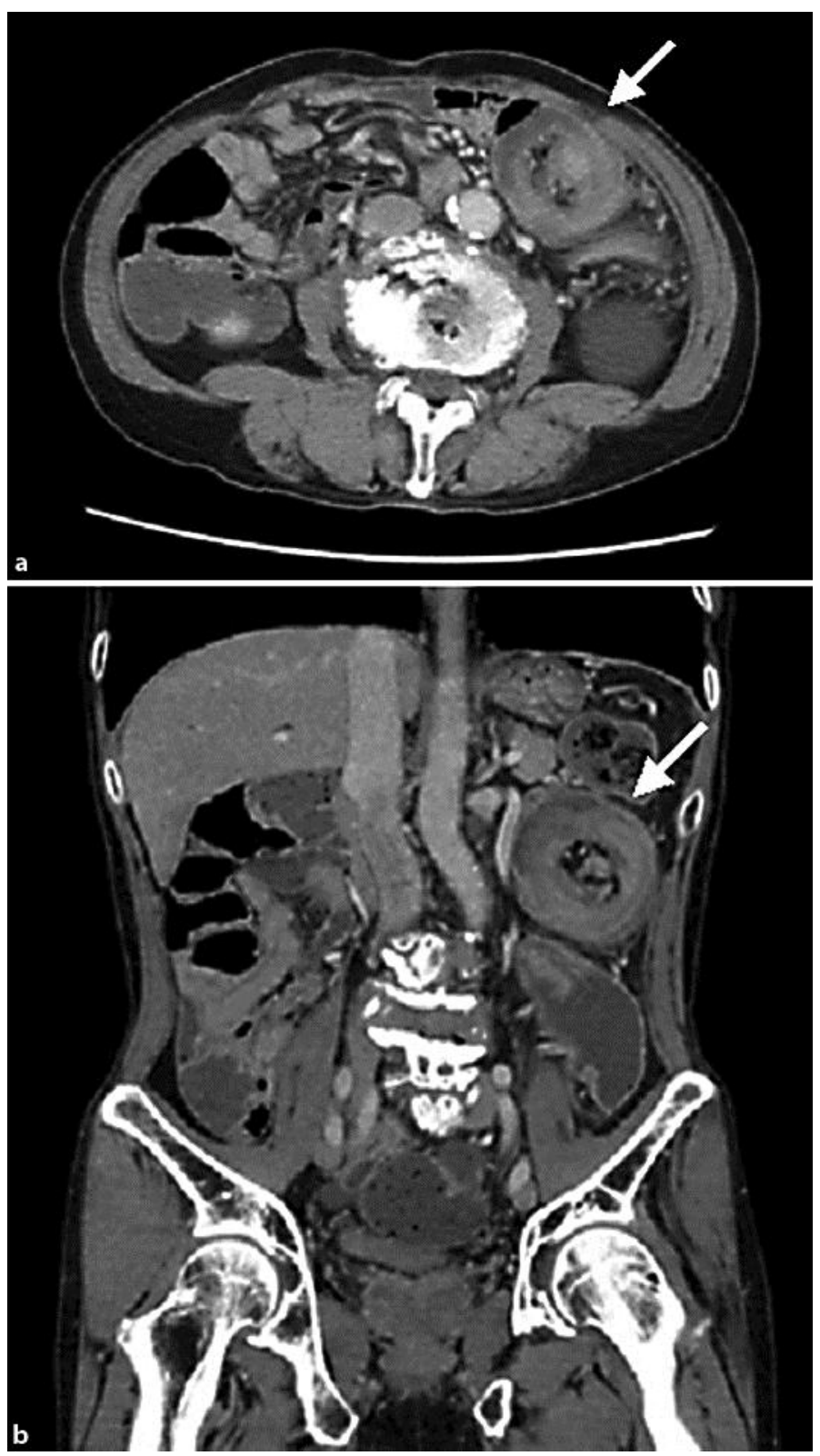

Fig. 1. Abdominal CT indicated enlargement of the descending colon wall within the intussusception (arrows), suggesting the existence of a tumor in the head. a Transverse slice. $\mathbf{b}$ Sagittal slice. 


\begin{tabular}{r|l|l|l}
$\begin{array}{r}\text { Case Reports in } \\
\text { Gastroenterology }\end{array}$ & $\begin{array}{l}\text { Case Rep Gastroenterol 2012;6:88-93 } \\
\text { DOI: 10.1159/000336601 }\end{array}$ & $\begin{array}{l}\text { Published online: } \\
\text { January 31, 2012 }\end{array}$ & $\begin{array}{l}\text { @ 2012 S. Karger AG, Basel } \\
\text { ISSN 1662-0631 } \\
\text { www.karger.com/crg }\end{array}$ \\
\hline
\end{tabular}

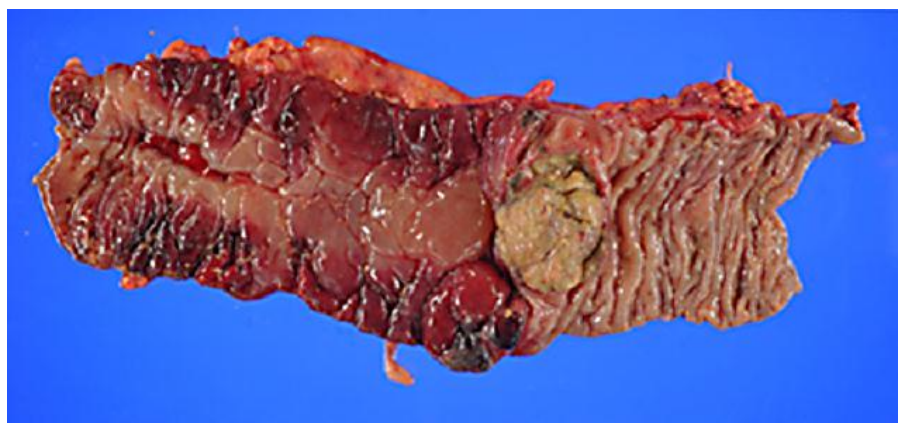

Fig. 2. The surgical specimen contained a $5.3 \times 3.5 \mathrm{~cm}$ protuberant tumor that was thought to be the lead point of the intussusception. The ischemic area of the wall was $16 \mathrm{~cm}$ along the anal side of the tumor.
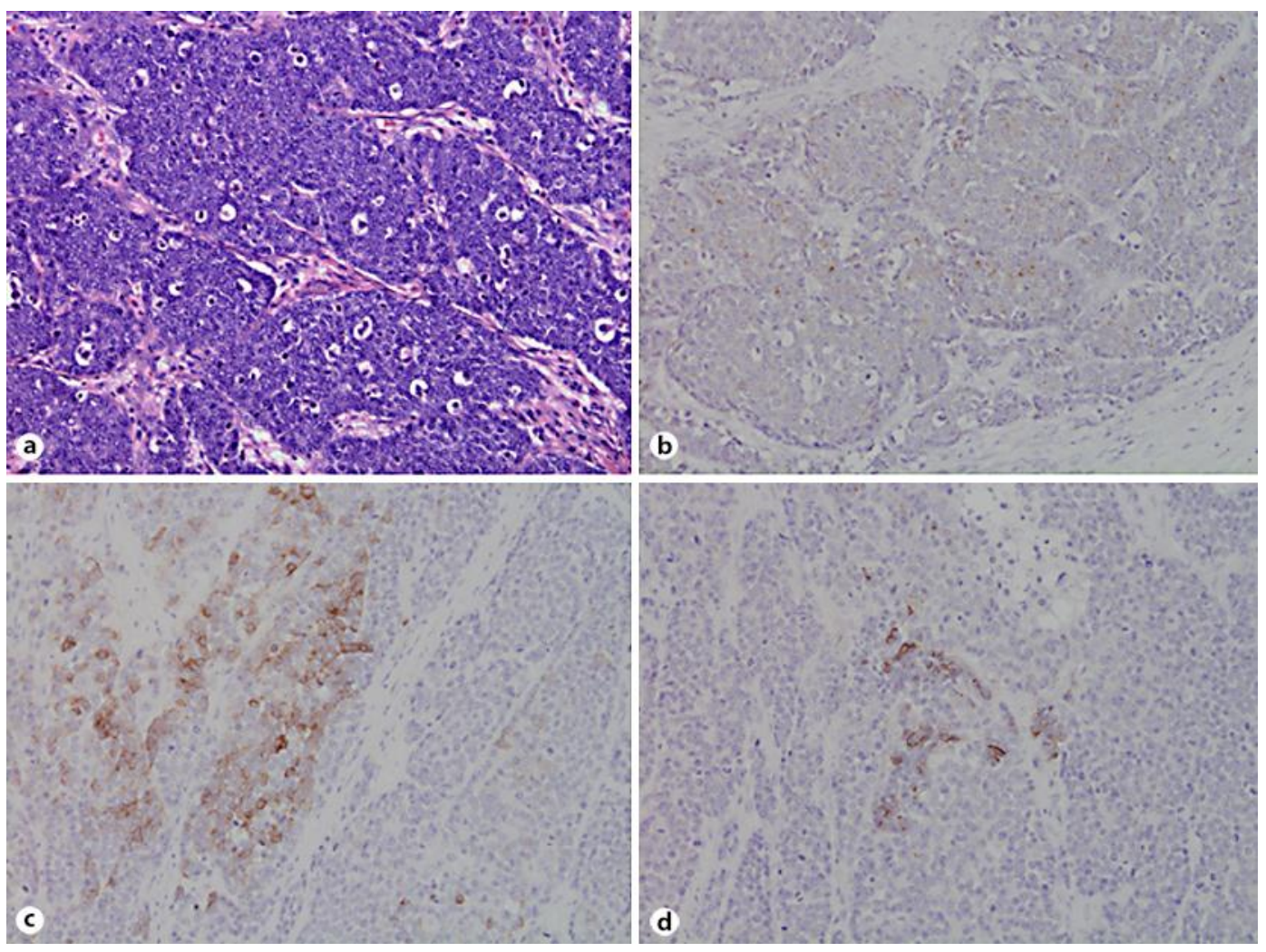

Fig. 3. Microscopic examination. a The tumor was a poorly differentiated adenocarcinoma with invasion into the subserosa (hematoxylin-eosin staining, $\times 100$ ). $\mathbf{b}$-d The tumor was partially positive for chromogranin A, KIT, and CD56 by immunohistological staining $(\times 100)$. 


\section{References}

1 Azar T, Berger DL: Adult intussusception. Ann Surg 1977;226:134-138.

-2 Warshauer DM, Lee JK: Adult intussusception detected at CT or MR imaging: clinical-imaging correlation. Radiology 1999;212:853-860.

3 Begos DG, Sandor A, Modlin IM: The diagnosis and management of adult intussusception. Am J Surg 1997;173:88-94.

-4 Karimata H, Ikemamatsu Y, Fujitani K, Inokuma T, Matsuo K, Kuroda H, Yamamoto Y, Nishiwaki Y, Kida H, Waki S: Descending colon cancer associated with intussusception (in Japanese with English abstract). Nihon Syoukakigeka Gakkaizasshi (Jpn J Gastroenterol Surg) 2004;37:1664-1667.

5 Shioda Y, Koizumi S, Furuya S, Akira S, Kameyama N, Hamano N, Takahashi W, Tokunaga A, Tanaka N Onda M: Intussusception caused by a carcinoma of the cecum during pregnancy: report of a case and review of the literature. Surg Today 1993;23:556-561.

6 Matsuda K, Suda K, Tamura K, Deguchi T, Yamazaki E, Yago H, Inaba T, Takeshima T, Adachi M, Okinaga K: Surgical management of adult sigmoid colon intussusception caused by a malignant tumor: report of a case. Surg Today 2003;33:768-771.

7 Bar-Ziv J, Solomon A: Computed tomography in adult intussusception. Gastrointest Radiol 1991;16: 264-266.

-8 Nagorney DM, Sarr MG, McIlrath DC: Surgical management of intussusception in the adult. Ann Surg 1981;193:230-236.

9 Glisson BS, Moran CA: Large-cell neuroendocrine carcinoma: controversies in diagnosis and treatment. J Natl Compr Canc Netw 2011;9:1122-1129. 